\title{
Study on array laterolog response simulation and mud-filtrate invasion correction
}

\author{
Peiqiang Zhao ${ }^{1,2 \oplus}$, Ruidong Qin ${ }^{3}$, Heping Pan $^{1 *}$, Mehdi Ostadhassan ${ }^{2}$, Yuqi Wu ${ }^{4}$ \\ ${ }^{1}$ Institute of Geophysics and Geomatics, China University of Geosciences, Wuhan 430074, P. R. China \\ ${ }^{2}$ Department of Petroleum Engineering, University of North Dakota, Grand Forks 58201, ND, USA \\ ${ }^{3}$ Three Gorges Geotechnical Consultants Co., Ltd., Changjiang Institute of Survey, \\ Planning, Design and Research, Wuhan 430074, P. R. China \\ ${ }^{4}$ Department of Petroleum Engineering, University of Wyoming, Laramie 82071, WY, USA
}

(Received Feburary 27, 2019; revised March 5, 2019; accepted March 6, 2019; available online March 10, 2019)

\section{Citation:}

Zhao, P., Qin, R., Pan, H., Ostadhassan, M., Wu, Y. Study on array laterolog response simulation and mud-filtrate invasion correction. Advances in Geo-Energy Research, 2019, 3(2): 175-186, doi: 10.26804/ager.2019.02.07.

Corresponding author:

*E-mail: panpinge@163.com

Keywords:

Array laterolog

numerical simulation

finite element method

mud-filtrate invasion

\begin{abstract}
:
It is a complicated task to evaluate the reservoirs influenced by mud-filtrate invasion. This study presents numerical simulation results of array laterolog response and the approach for mud-filtrate invasion correction. Considering differential equations and boundary conditions of the steady current field in the rock medium, finite element method is utilized to solve the Laplace equation. Then the potential value at each node is calculated along with the apparent resistivity of six measuring modes of array laterolog. Based on the numerical results, the array laterolog response is affected by various parameters including borehole radius, mud-filtrate resistivity, mud-filtrate invasion radius and invaded zone resistivity. Correction charts for borehole and mud-filtrate invasion are developed to accurately obtain the mud-filtrate invasion depth and the true resistivity of the uninvaded formation. The correction chart has been applied to the real array laterolog data of a sandstone reservoir, which the corrected resistivity is closer to the true formation resistivity.
\end{abstract}

\section{Introduction}

In drilling process, the pressure difference between the borehole fluid and the formation drives the mud-filtrate to invade into permeable zones (Yang et al., 2017). As a result, the resistivity distribution of the formation gets affected, makes the electrical response deviate from true resistivity of the formation (Salazar and Martin, 2012; Windarto et al., 2012). This happens due to the influence of mud-filtrate invasion, which makes the identification and evaluation of reservoirs (pay zone) challenging.

Schlumberger developed a high-resolution array tool (HRLA) (Chen et al., 1998; Smits et al., 1998), which provides six electric log curves with different radial detection and depth of investigation to characterize the formation with higher vertical resolution and more radial coverage (Griffiths et al., 1999; Dun et al., 2010; Deng et al., 2011). In addition to the HRLA and high-definition lateral log (HDLL) developed by Western Atlas (Itskvich et al., 1998), CNPC Logging company also developed its array laterolog tool (HAL) (He et al., 2013). Though regardless of the developer, all of these instruments are inevitably affected by borehole condition (including drilling fluid resistivity and borehole diameter) and mud-filtrate invasion during the detection process (Phelps, 1995). Therefore, borehole and mud-filtrate invasion correction of raw array laterolog data is a critical step to represent the formation. Griffiths et al. (2000) summarized the limitations of traditional lateral and induction logging. He proposed that the data acquired by the array instruments could reduce various uncertainties due to borehole conditions and improve the accuracy and reliability of formation resistivity. Frenkel and Walker (2001) obtained more accurate estimation of water saturation by using multidimensional inversion processing in the logging analysis. Galli et al. (2002) applied twodimensional (2D) resistivity forward and inversion techniques to describe the petrophysical properties of the reservoir, such as water saturation, which can correct the effects of several environmental factors in real time, as well as provide water 
saturation of thin sandstone layers with abnormal invasion. Maurer et al. (2009) developed a set of model-based adaptive borehole correction technology to overcome the influence of borehole and eccentricity in shallow measurements, and further improved the accuracy of formation parameter estimation using two-dimensional inversion. According to the modelbased adaptive borehole correction technology, Abdel-Shafy (2011) believed the corrected uninvaded formation resistivity is evidently higher than the values measured in the deepest lateral direction, and provides a feasible method to estimate the invasion depth of mud. Nie et al. (2015) proposed a multi-array laterolog tools and methods that using split monitor electrodes enable accurately measure the electrode potential. $\mathrm{Li}$ and Bittar (2016) developed a focused array laterolog that can provide for focused measurements.

In China, Liu et al. (2002, 2005), Yang (2003) and Wu et al. (2008) achieved the 2D array lateral response of the model simulation with finite element method (FEM) (Wang et al., 2013). Jiang (2009) studied the numerical simulation of non-uniform array laterolog response under the inclined geological conditions. Deng et al. (2010) used generalized curvilinear coordinate system to simulate mud-filtrate invasion characteristics in the inclined well, and then studied array laterolog response of mud-filtrate invasion process. Pan et al. (2013) deduced the Robin boundary conditions on the infinite truncation boundary for the axisymmetric formation model including borehole, invasion zone, shoulder rock and target layer, and established the boundary value problem model of the equivalent surface for the high-resolution array laterolog. Pan et al. (2016) proposed a method for forward problem based on the superposition principle and parallel direct solver to calculation of array laterolog responses. However, the literature that combines simulation of array laterolog response with correction chart development and practical applications is rare.

In this paper, the boundary condition of array laterolog is derived from the axisymmetric formation model including borehole, invasion zone and target formation. It is converted by variational method to achieve the extreme value of a function, which is solved through FEM approach to obtain the apparent resistivity value of each detection mode. In view of the influence of borehole conditions and invasion zone on the array laterolog response, different formation models are established and their apparent resistivity is calculated. This enables us to analyze the impact of various borehole conditions on the array laterolog response to create a mud-filtrate invasion correction chart. In the next step, the actual array laterolog data is processed with this proposed mud-filtrate invasion correction chart, to provide us with the mud-filtrate invasion radius and uninvaded formation resistivity, which can better represent the reservoir (pay zone) petrophysical characteristics.

\section{Theory and method}

\subsection{Array laterolog measurement}

The array laterolog device combines multiple focusing coils, consisting of a main electrode $A_{0}$, six pairs of shielding electrodes $A_{i}, A_{i}^{\prime}(1 \leqslant i \leqslant 6)$, and six pairs of monitoring electrodes $M_{i}, M_{i}^{\prime}(1 \leqslant i \leqslant 6)$. These electrodes are symmetric with respect to the main current electrode $A_{0}$, as shown in Fig. 1. At each measuring mode, the current electrode $A_{0}$ emits unit current $I_{0}$, while the monitoring electrodes do not. The shallowest detection depth HAL0 is obtained when only $A_{0}$ emits current and other shielding electrodes are acting as return electrodes. By adding a pair of shielding electrodes to both sides of $A_{0}$ at various modes of measurement, HAL1, HAL2, HAL3, HAL4, and HAL5 of array laterolog with different detection depths can be attained successively. HAL0 mainly detects the resistivity of mud and borehole, and the detection depth of HAL1 HAL5 gradually increases, thus reflecting the change of radial resistivity of the formation.

The HAL0 detection mode measures the potential difference between the monitoring electrode $M_{1}$ and $M_{2}$. Other detection modes measure the potential $U_{A 0}$ and the current value on the main electrode $A_{0}$. The formulas for calculating the apparent resistivity are as follows (Jiang, 2009):

$$
\begin{gathered}
R_{H A L, 0}=K_{H A L, 0} \frac{U_{M_{1}}-U_{M_{2}}}{I_{A_{0}}} \\
R_{H A L, i}=K_{H A L, i} \frac{U_{M_{i}}}{I_{A_{0}}}(i=1,2, \cdots, 5)
\end{gathered}
$$

where $K_{H A L, i}$ is the geometric coefficient value of HAL $i(i=1$, $2, \ldots, 5) ; U_{M_{1}}$ is the potential value at the $M_{1}$ electrode; $U_{M_{2}}$ is the potential value at the $M_{2}$ electrode; $I_{A_{0}}$ is the current intensity emitted by the $A_{0}$ electrode; $R_{H A L, i}$ is the apparent resistivity measured by different measurement modes.

\subsection{Numerical simulation of array laterolog response with FEM}

The laterolog tool utilizes low frequency alternating current, which can be treated as a steady current (approximately). The electric field formed by this steady current is essentially similar to the electrostatic field. In the case of a 2D axial symmetry and cylindrical coordinate system, the field calculated by the array laterolog can be simplified to a two-dimensional nonuniform medium model (Fig. 1). The equations and boundary conditions controlling the electric field are as follows ( $\mathrm{Li}$ et al., 1980; Pan et al., 2013; Jarzyna et al., 2016):

$$
\begin{gathered}
\frac{\partial}{\partial r}\left(\frac{r}{\rho} \frac{\partial U}{\partial r}\right)+\frac{\partial}{\partial z}\left(\frac{r}{\rho} \frac{\partial U}{\partial z}\right)=0 \\
\left.U\right|_{\Gamma_{a}}=0
\end{gathered}
$$

$$
\left.\frac{\partial U}{\partial n}\right|_{\Gamma_{b}}=0
$$

$$
\left\{\begin{array}{l}
\left.U\right|_{\Gamma_{I}}=C_{A_{i}} \\
\int \frac{2 \pi r_{0}}{\rho} \frac{\partial u}{\partial n} d l=I_{I}
\end{array}\right.
$$




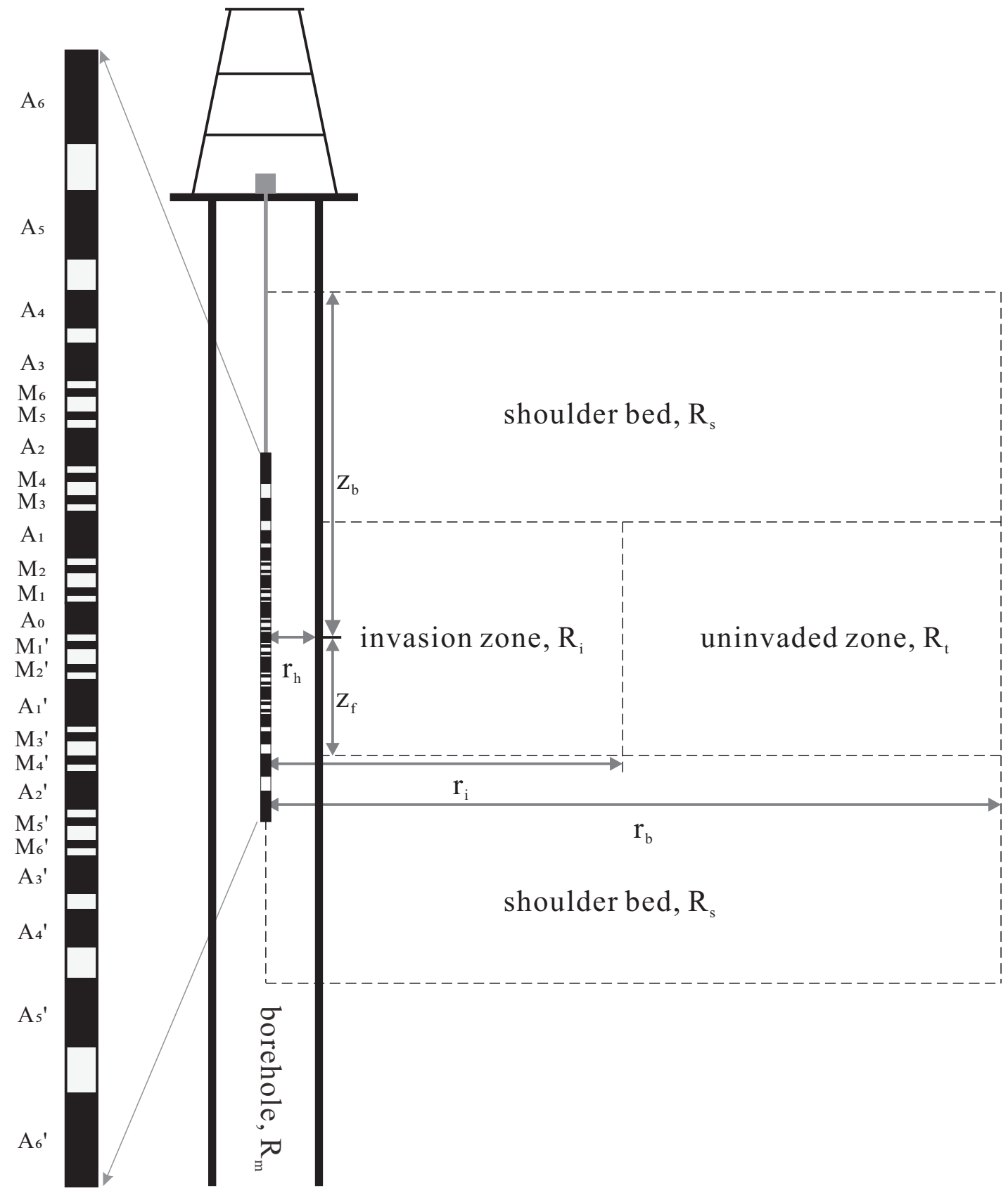

Fig. 1. Array laterolog device and formation model for numerical simulation.

$$
\left\{\begin{array}{l}
\left.U_{-}\right|_{\Gamma_{c}}=\left.U_{+}\right|_{\Gamma_{c}} \\
\left.\frac{1}{\rho_{-}}\left(\frac{\partial U}{\partial \boldsymbol{n}}\right)\right|_{\Gamma_{C}}=\left.\frac{1}{\rho_{+}}\left(\frac{\partial U}{\partial \boldsymbol{n}}\right)_{+}\right|_{\Gamma_{C}}
\end{array}\right.
$$

where the value of the resistivity $\rho$ varies in different regions.

$$
\rho=\left\{\begin{array}{l}
R_{m}, \text { in borehole } \\
R_{i}, \text { in invasion zone } \\
R_{s}, \text { in shoulder bed } \\
R_{t}, \text { in uninvaded zone }
\end{array}\right.
$$

Eq. (3) is called Laplace equation. Eq. (4) means that potential on the infinite boundary is very small and can be neglected. Eq. (5) describes the insulation boundary. Eq. (6) illustrates the $i$ th electrode surface is an equipotential body $(0 \leqslant i \leqslant 12)$. Eq. (7) indicates the interface of different formations. These conditions are set although the resistivity mutations in the interface $\Gamma_{c}$, the potential $U$ and current intensity on either side of the interface are continuous.

When the array laterolog device is in operation, the main electrode $A_{0}$ and the shielding electrodes emit current simultaneously and generate the electric field. However, the current value on each shielding electrode is unknown, thus it should be adjusted to meet the equipotential condition. 
Therefore, the electric field superposition principle is adopted to transform the potential function into the superposition of potential functions of multiple sub-fields (Pan et al., 2013):

$$
U^{(i)}=U_{0}+\sum_{m=1}^{6} I_{m}^{(i)} U_{m}
$$

Sub-field 1 only supplies current $I_{0}=1$ to main electrode $A_{0}$, while other electrodes do not supply the current. Sub-field $n$ only provides current $I=1$ to the shielding electrode $A_{n}$, ( $n=1,2, \ldots, 6)$, while other electrodes do not provide any current. Therefore, the potential distribution of a total of 7 sub-fields can be figure out and written as: $U_{0}(r, z), U_{1}(r, z)$, $U_{2}(r, z), U_{3}(r, z), U_{4}(r, z), U_{5}(r, z)$, and $U_{6}(r, z)$. According to the linear superposition principle, the total response of the $i$ th measurement mode, HAL $i$ is shown in Eq. (9). Where, $I_{m}^{(i)}$ represents the shielding electrode $A_{m}(m=1,2, \ldots, 6)$. The value is the undetermined constant representing the focusing synthesis coefficient of the instrument, and the potential value on each electrode should meet the equal potential condition.

For the $i$-th measurement mode, the six element linear equations satisfying $I_{m}^{(I)}$ can be obtained by using the equilibrium conditions. By solving the equations, the current emission value on the shielding electrode during the $i$-th measurement can be obtained.

Considering the boundaries on the above value problem, the following functional can be established (Zhang, 2009):

$$
\begin{gathered}
\boldsymbol{\Phi}(U)=\frac{1}{2} \iint \frac{r}{\rho}\left[\left(\frac{\partial U}{\partial r}\right)^{2}+\left(\frac{\partial U}{\partial z}\right)^{2}\right] d r d z-\sum I_{\Gamma_{i}} U_{\Gamma_{i}} \\
\boldsymbol{\Phi}(U)=\boldsymbol{\Phi}_{1}(U)-\boldsymbol{\Phi}_{2}(U)
\end{gathered}
$$

where $I_{\Gamma_{i}}$ is the total current on the electrode; $\boldsymbol{\Phi}_{1}$ indicates the half of consumed power in the solved area; $\boldsymbol{\Phi}_{2}$ is the power provided by the electrodes. Thus, the physical meaning of the functional is the difference of half power consumption and electrode supplied power (Zhang, 2009). As a result the boundary value problems, i.e., Eqs. (3)-(7) can be transformed into a functional extreme value problem through the following relationship:

$$
\Phi(u)=\min \Phi(U)
$$

In other words, only $U$ is in existence which can make functional $\boldsymbol{\Phi}(U)$ to achieve the minimum.

In this study, triangular mesh is applied to subdivide the solution region. Although the triangular mesh is not as accurate as quadrilateral mesh in terms of calculation accuracy, triangular mesh has a strong adaptability, and can be easily divided into irregularly shaped areas for solution, and the description of the study area is also smoother. In this paper, MATLAB grid kit is used for grid generation. Then, the optimal linear interpolation function is selected to interpolate the function value on each element. The integral in Eq. (10) is decomposed into the integral on each element, and finally the integral on each element is summed to synthesize the stiffness matrix and obtain the load vector. The linear equations are obtained according to the variational principle. After the equipotential surface treatment, the potential values of each node in the solution region can be obtained by solving the linear equations. Finally, the apparent resistivity of the array laterolog is calculated according to Eqs. (1) and (2).

\section{Simulation results}

\subsection{Potential distribution}

The formation model for the numerical simulation is designed as follows: In the absence of shoulder bed and mud intrusion, the formation radial radius $r_{b}=40 \mathrm{~m}$, formation thickness $Z_{b}=40 \mathrm{~m}$, borehole radius $r_{h}=0.1 \mathrm{~m}$, resistivity of mud filtrate $R_{m}=0.1 \Omega \cdot \mathrm{m}$, resistivity of the formation $R_{t}$ $=1 \Omega \cdot \mathrm{m}$. The main electrode $A_{0}$ emits current $I_{0}=1$.

Fig. 2 shows the potential distribution of the six detection modes of HAL0 HAL5. From the HAL0 to the HAL5 detection mode, a pair of shielding electrodes are added each time, thereby causing the current to flow deeper into the formation. Thus, the current from the main electrode and the shielding electrodes have an effect on larger regions, allowing different detection modes to reflect the resistivity at different radical depths.

\subsection{Effect of borehole radius on apparent resistivity}

The formation model discussed in this paper contains only borehole with the radius (caliper), $r_{h}$ varying from 0.1 to $0.34 \mathrm{~m}$ and the layers with infinite thickness. The mud-filtrate resistivity $\left(R_{m}\right)$ is $0.1 \Omega \cdot \mathrm{m}$, and the formation resistivity $\left(R_{t}\right)$ is set to $10 \Omega \cdot \mathrm{m}$. The numerical simulation result is shown in Fig. 3 . When the borehole radius is $0.1 \mathrm{~m}$, the apparent resistivities of 5 detection models are equal to the true formation resistivity. As the borehole radius increases, the impact of mud-filtrate also increases gradually. Consequently, apparent resistivities of all 5 detection models are reduced. It is found that borehole radius has the maximum impact on the HAL1 detection mode, but the minimum on the apparent resistivity of HAL5. Finally, when the borehole radius is less than $0.25 \mathrm{~m}$, HAL5 is basically unaffected.

\subsection{Effect of invasion radius on apparent resistivity}

We only simulate the low resistivity mud-filtrate invasion model since array laterolog is not applied to oil-based mud. The formation model is established as shown in Table 1, and the numerical simulation results are shown in Fig. 4. The area affected by the mud-filtrate invasion increases with the increase of invasion radius. When the invasion radius is $1 \mathrm{~m}$, apparent resistivities of 4 detection modes becomes stagnant (except the HLA5), which indicates the depth of investigation (DOI) of array laterolog device. The apparent resistivity of HAL1 is affected by the invasion radius mostly, which gradually approaches the invaded zone resistivity. 
Table 1. The formation model for mud-filtrate invasion.

\begin{tabular}{lllll}
\hline \multirow{2}{*}{ Formation model } & Formation resistivity & Invasion zone resistivity & Mud-filtrate resistivity & $\begin{array}{l}\text { Borehole radius } \\
r_{h}(\mathrm{~m})\end{array}$ \\
& $R_{t}(\Omega \cdot \mathrm{m})$ & $R_{i}(\Omega \cdot \mathrm{m})$ & $R_{m}(\Omega \cdot \mathrm{m})$ & 0.1 \\
\hline Low resistivity mud-filtrate invasion & 10 & 1 & 0.1 & 0.1 \\
\hline
\end{tabular}
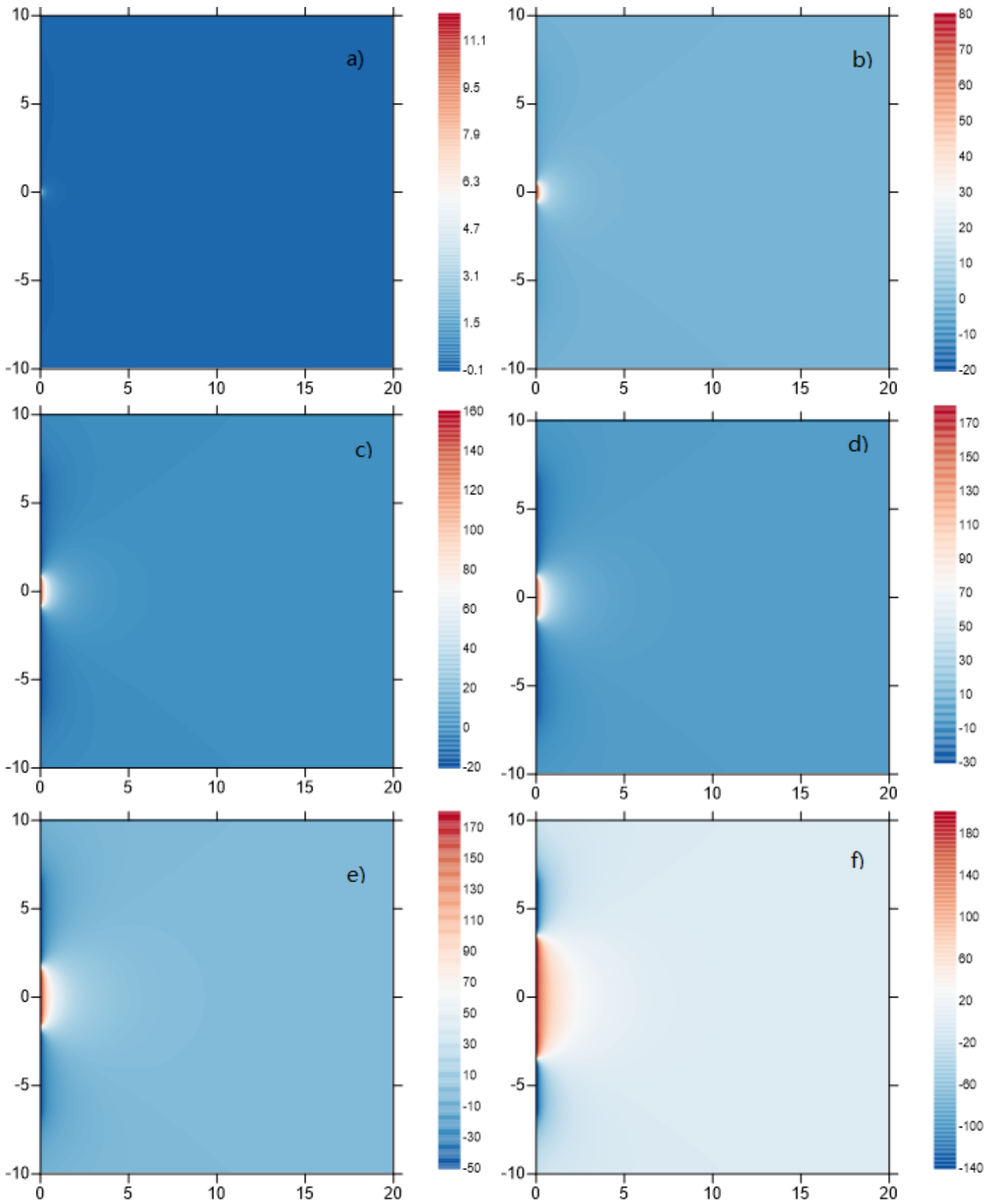

Fig. 2. The simulated potential distribution. a) HALO detection mode; b) HAL1 detection mode; c) HAL2 detection mode; d) HAL3 detection mode; e) HAL4 detection mode; f) HAL5 detection mode. The ordinate is the formation depth and the abscissa is the radial radius. Color scale indicates the potential. 


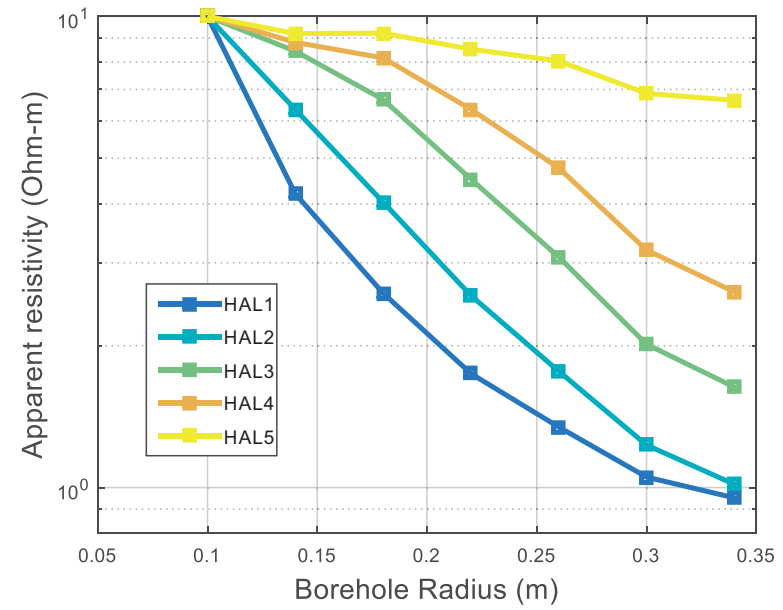

Fig. 3. Effect of borehole radius on apparent resistivity.

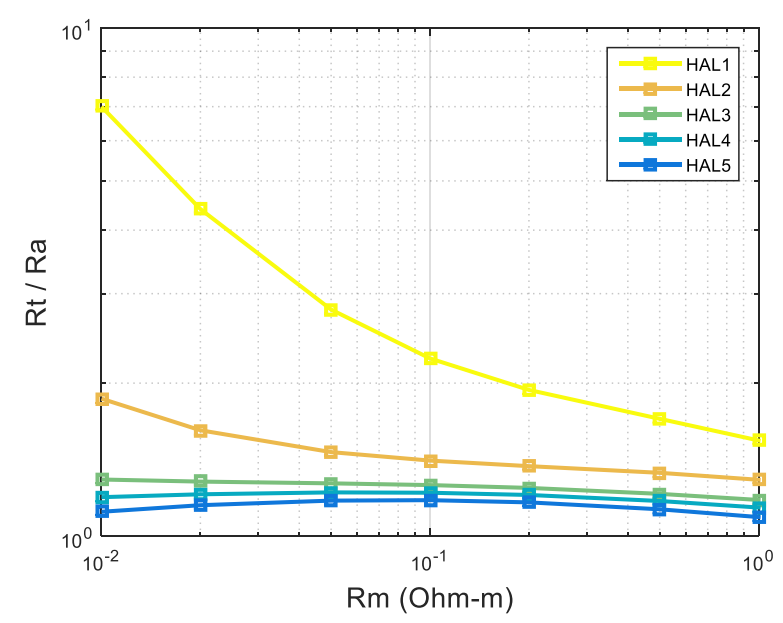

Fig. 5. Apparent resistivity varies with mud-filtrate resistivity.

\subsection{Effect of mud-filtrate resistivity on apparent re- sistivity}

The formation model without the influence of surrounding rocks is studied in this section. Borehole radius $r_{h}$ is $0.1 \mathrm{~m}$, invasion zone resistivity $R_{i}$ is $1 \Omega \cdot \mathrm{m}$, and uninvaded zone resistivity $\left(R_{t}\right)$ is $10 \Omega \cdot \mathrm{m}$, mud-filtrate resistivity varies from 0.01 to $1 \Omega \cdot \mathrm{m}$. The numerical simulation results are shown in Fig. 5. The apparent resistivity of HAL1 is mostly affected by mud-filtrate resistivity. If the mud-filtrate resistivity is greater than $0.05 \Omega \cdot \mathrm{m}$, its apparent resistivity decreases gradually. Considering other detection modes with deeper DOI, the apparent resistivities are not much affected by the change of mud-filtrate resistivity. However, all ratios of $R_{t} / R_{a}$ are greater than 1, reflecting that the array laterolog responses of all detection modes are affected by the mud-filtrate with lower resistivity. Therefore, the apparent resistivity becomes less than the true formation resistivity.

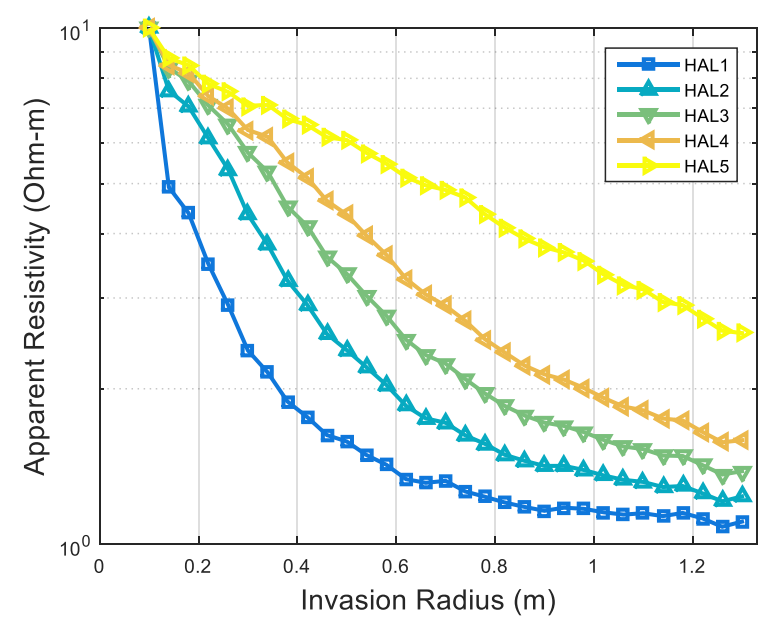

Fig. 4. Apparent resistivity varies with intrusion radius in the low resistivity mud-filtrate invasion model.

\subsection{Effect of invasion zone resistivity on apparent resistivity}

Mud-filtrate invasion is an important feature of permeable formations, which makes the radial resistivity profile of the formation to become a step model or a transition model. The fluid properties of the formation can be determined through the resistivity radial profiles. Formation model established in this section includes following parameters: Borehole radius $r_{h}$ is $0.1 \mathrm{~m}$, invasion radius varies from 0.1 to $1.3 \mathrm{~m}$, invasion zone resistivity varies from 0.1 to $10 \Omega \cdot \mathrm{m}$, and uninvaded zone resistivity is $10 \Omega \cdot \mathrm{m}$. The apparent resistivities of 5 detection modes vary with the invaded zone resistivity and invasion radius, shown in Fig. 6.

Fig. 6a illustrates the numerical apparent resistivity of HAL1 under the influence of invasion zone resistivity and invasion radius. The resistivity curves of different invasion zones tend to reach a plateau with the increase of invasion radius. In addition, with the increase of the invasion zone resistivity, the ratio of apparent resistivity to the true resistivity is gradually getting close to 1 if the invasion radius stays constant. Since HAL0 detection mode is also affected by the resistivity of mud-filtrate, the ratio of true formation resistivity to apparent resistivity of HAL1 is greater than 1 when $R_{i} / R_{t}$ equals to 1.

The variations of apparent resistivity of the HAL2 HAL5 detection modes are similar to HAL1 detection mode. However, in the case of low-resistivity mud invasion model, it is necessary to increase the invasion radius to a certain limit before the apparent resistivity can be significantly affected due to the larger detection depth of other detection modes. As shown in Fig. 6d, the apparent resistivity of HAL4 detection mode changes significantly with decrease in resistivity of the invasion zone after the invasion radius reaches $0.2 \mathrm{~m}$. In Fig. 6e, the apparent resistivity of the HAL5 detection mode changes significantly with the decrease in the resistivity of the invasion zone after the invasion radius is reached $0.4 \mathrm{~m}$. All of these observations reflect the detection depth of different 


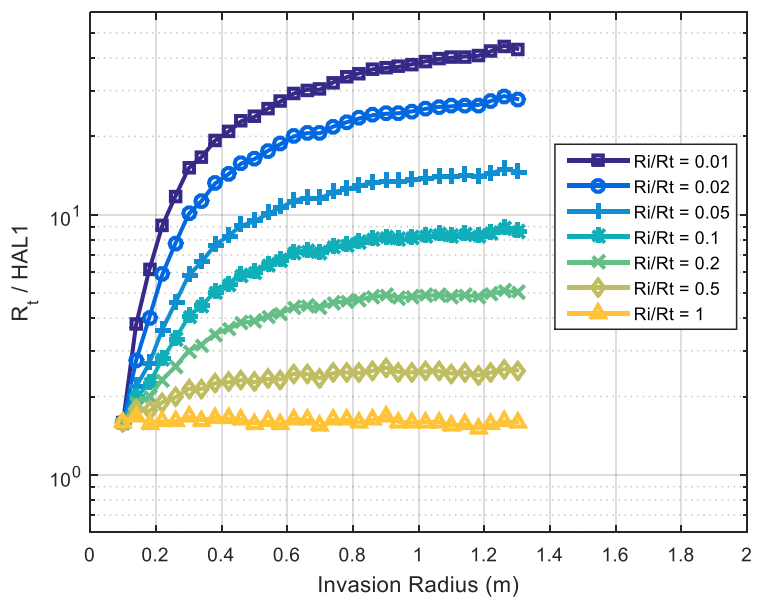

(a) HAL1 detection mode.

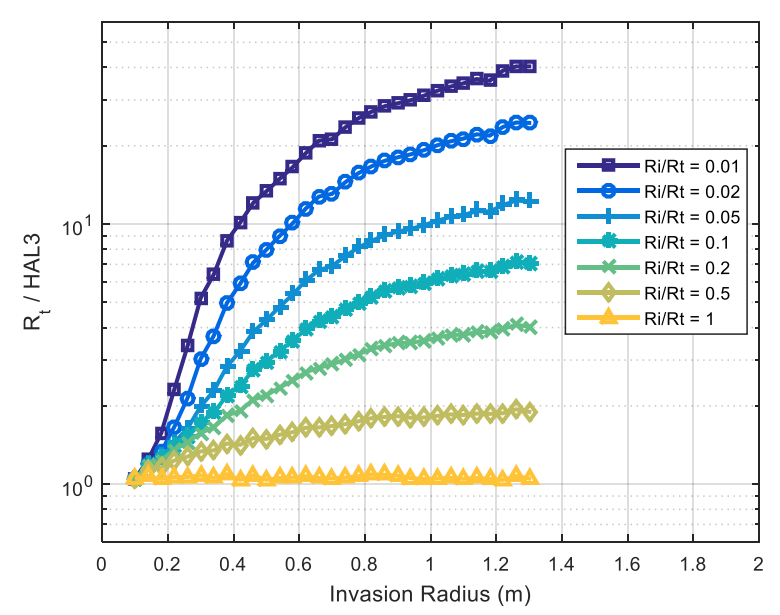

(c) HAL3 detection mode.

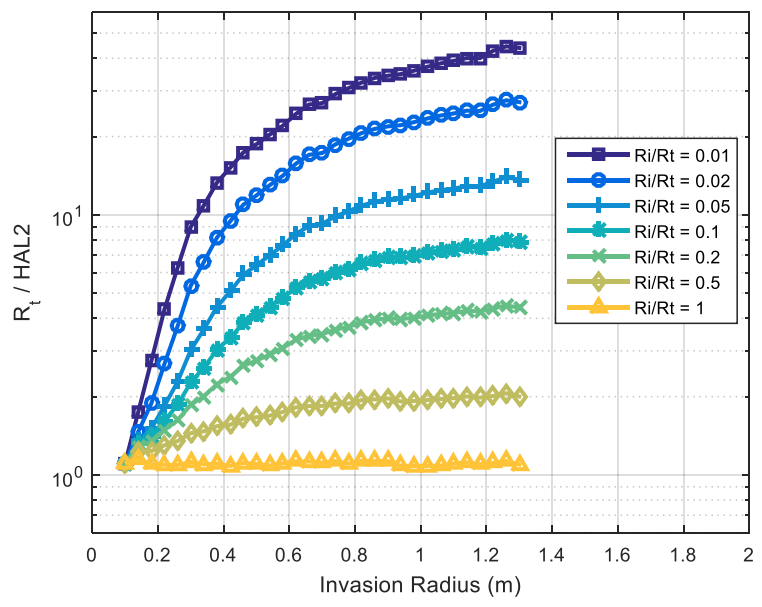

(b) HAL2 detection mode.

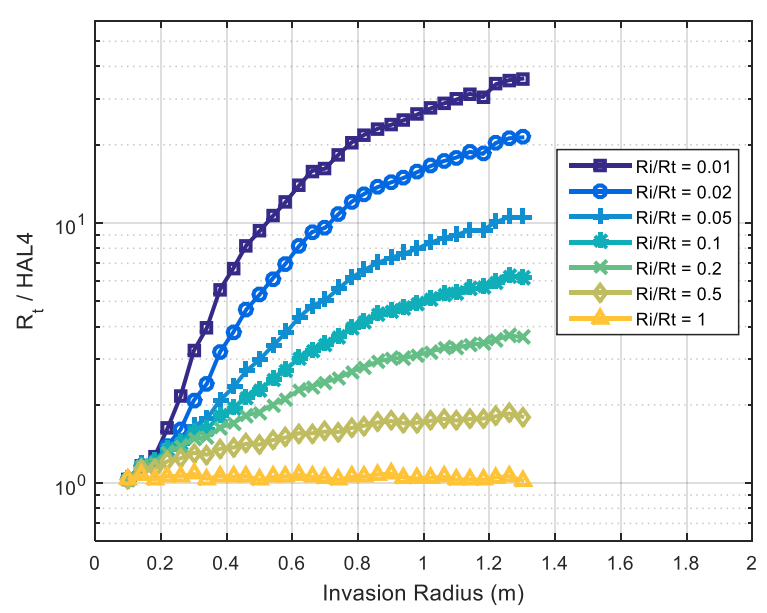

(d) HAL4 detection mode.

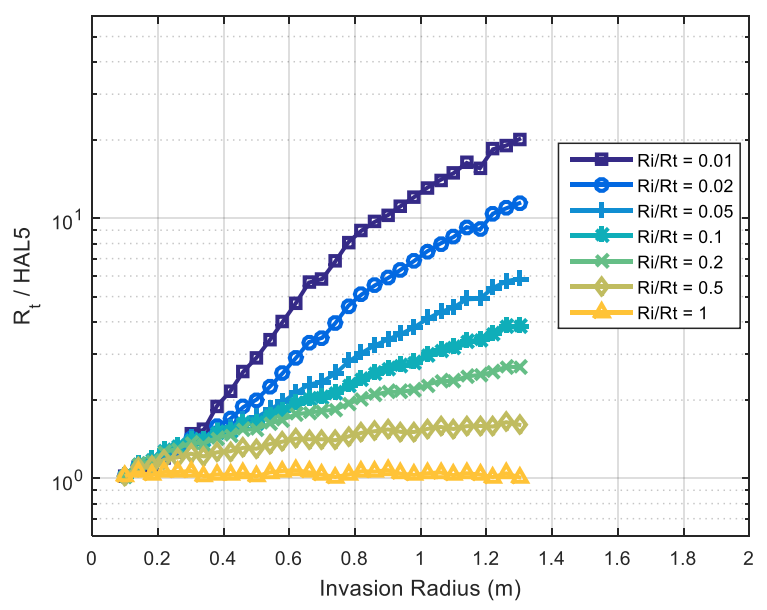

(e) HAL5 detection mode.

Fig. 6. The effect of invasion zone resistivity and invasion radius on apparent resistivity. 


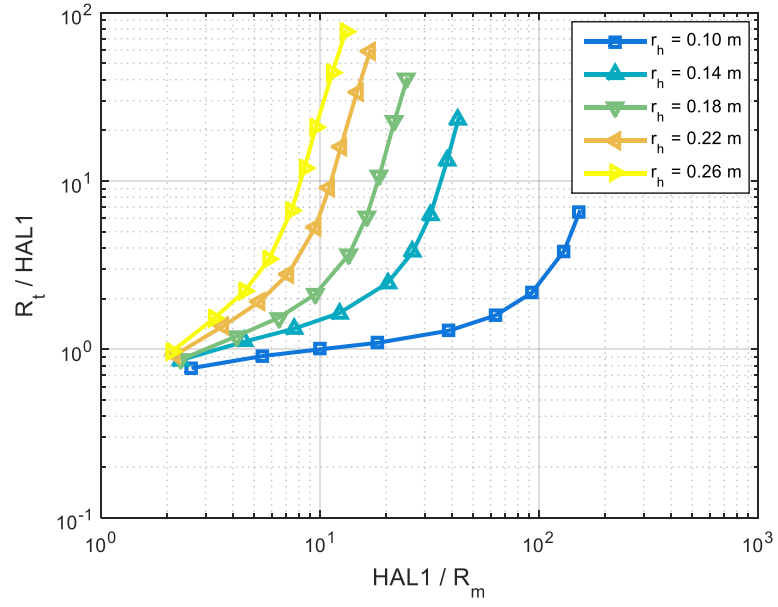

(a) HAL1 detection mode.

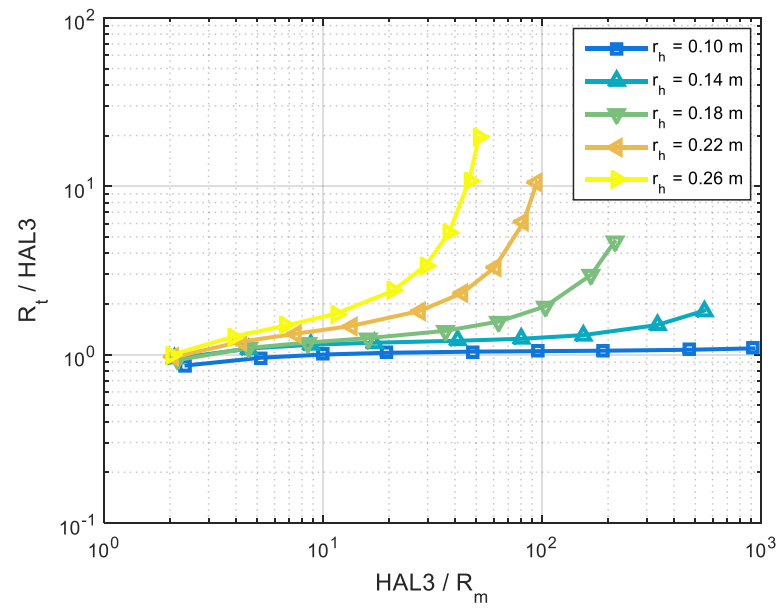

(c) HAL3 detection mode.

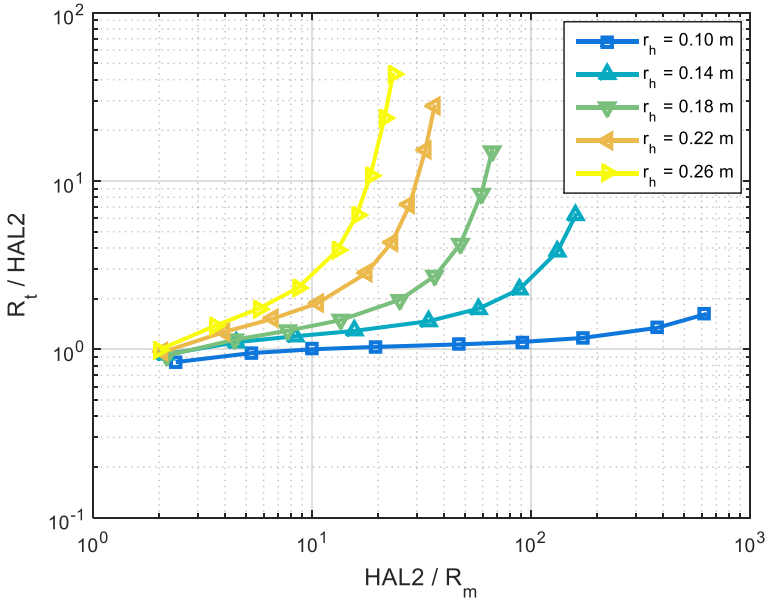

(b) HAL2 detection mode.

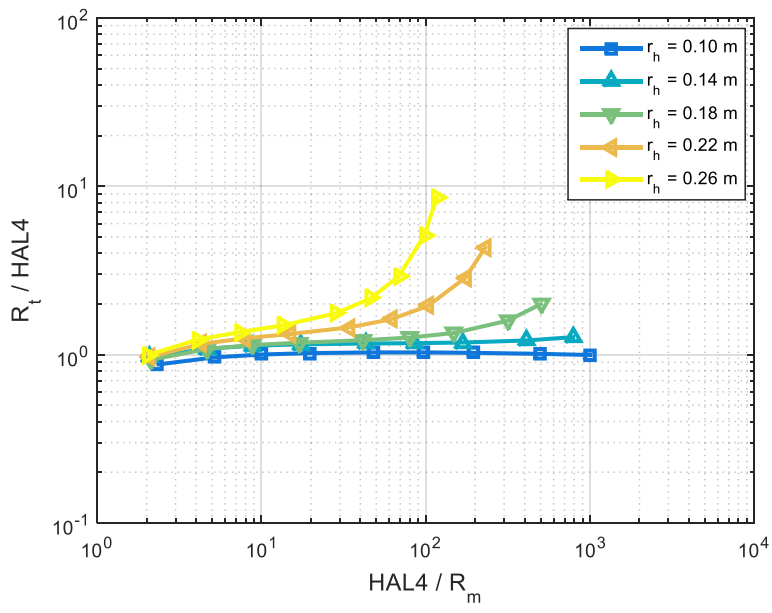

(d) HAL4 detection mode.

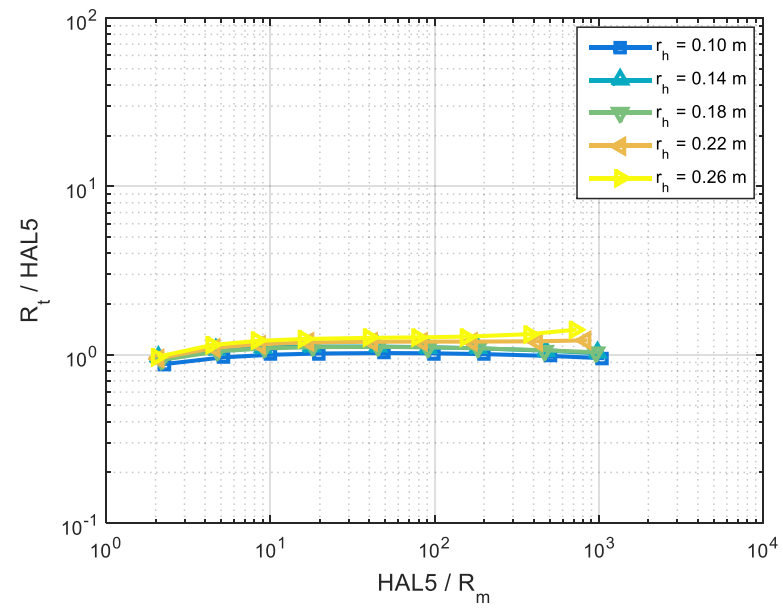

(e) HAL5 detection mode.

Fig. 7. The correction charts for borehole. 


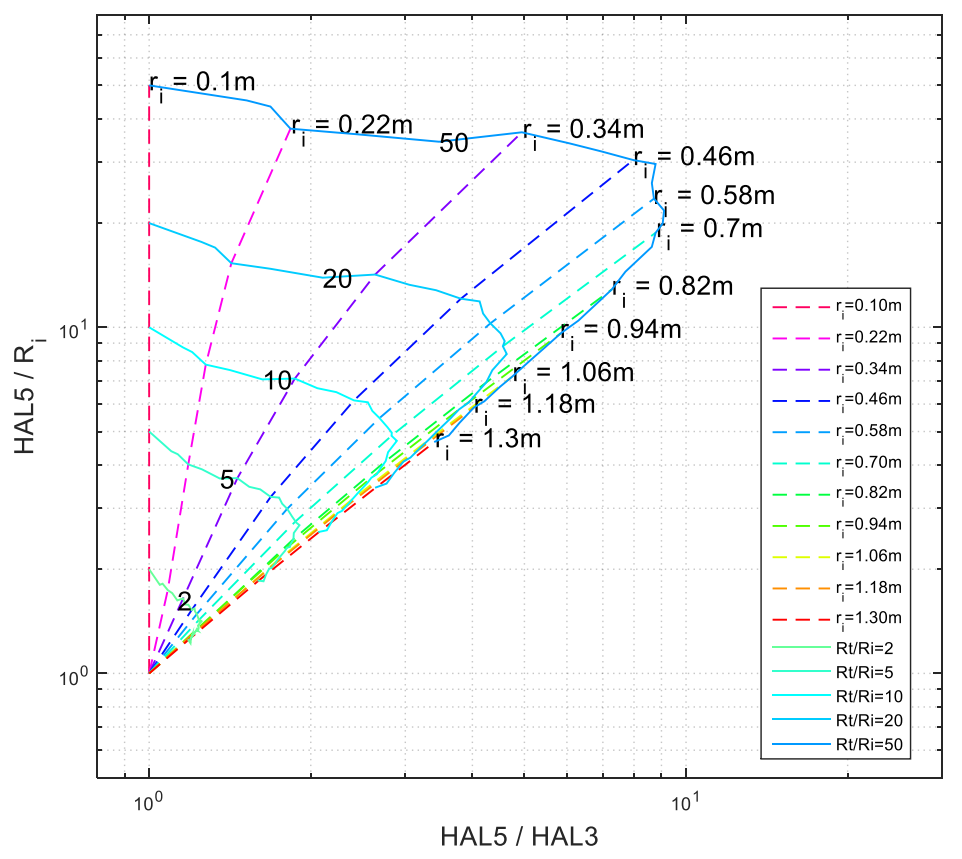

Fig. 8. The correction charts for mud-filtrate invasion.

detection modes.

\section{Correction charts}

Based on the analysis of the numerical simulation results above, the borehole and mud-filtrate invasion have a great influence on the array laterolog response. Thus, the interpretation results will be not accurate if the apparent resistivity curves measured by various detection modes are directly used to evaluate the formation. Therefore, correction charts should modify logging data to accurately represent the formation and its petrophysical characteristics. Based on the numerical simulation results of array laterolog, correction charts are made for the effect of borehole radius and mud-filtrate invasion, in particular.

\subsection{Borehole correction}

According to the formation model from different borehole radii, the array laterolog response values of HAL1 $\sim$ HAL5 are calculated. The resistivity curves of different borehole radii were plotted. The ratio of each array logging response to mudfiltrate resistivity as the abscissa and the ratio of true formation resistivity to array logging response as the ordinate, as shown in Fig. 7.

The application of the correction chart can be explained as follows: First, the resistivity $R_{m}$ of the mud-filtrate can be determined according to the resistivity of the mud-filtrate measured on site, and the log response value of HAL0 in the shallowest detection mode. Then, the radius $r_{h}$ is obtained by the caliper log. Finally, the corresponding $R_{t} / R_{a}$ ratio can be found in the charts to correct the apparent resistivity of each detection mode to the true formation resistivity.

\subsection{Mud-filtrate invasion correction}

In addition to the analysis that is laid out above for numerical simulation results of mud-filtrate invasion, the correction chart for mud-filtrate invasion is presented, as shown in Fig. 8. The ratio of resistivity of the deepest detection mode HAL5 to the middle detection mode HAL3 was selected as the abscissa, and the ratio of resistivity of the HAL5 detection mode to the invasion zone resistivity was used as the vertical coordinate. The dotted lines of different colors represent different invasion depths, and the solid lines are the results obtained from finite element numerical simulation.

In order to utilize this correction chart, first the apparent resistivity log values of HAL5 and HAL3 detection modes should be known. Then, the invaded zone resistivity $\left(R_{i}\right)$ should be obtained through shallow mode of dual laterolog, and calculate HAL5/HAL3 and HAL5/ $R_{i}$, respectively. Finally, by estimating the $R_{t} / R_{i}$ and plotting the data point on the chart, the invasion radius $r_{i}$, and true resistivity of formation can be obtained.

\section{Application}

After obtaining the apparent resistivity values of 5 detection modes in different layers, the mud-filtrate invasion depth and uninvaded formation resistivity of each layer can be corrected according to the mud-filtrate invasion correction chart in the previous section. We applied the mud-filtrate invasion correction chart to actual array laterolog data of a sandstone reservoir. The mud is salty, that is, low resistivity mud. The porosity of this formation is mainly distributed in the range of $6 \%-24 \%$, and the permeability mainly ranges from 3 to $33 \mathrm{mD}$. The oil saturation is high in the formation.

The processing results of the array laterolog data is shown 


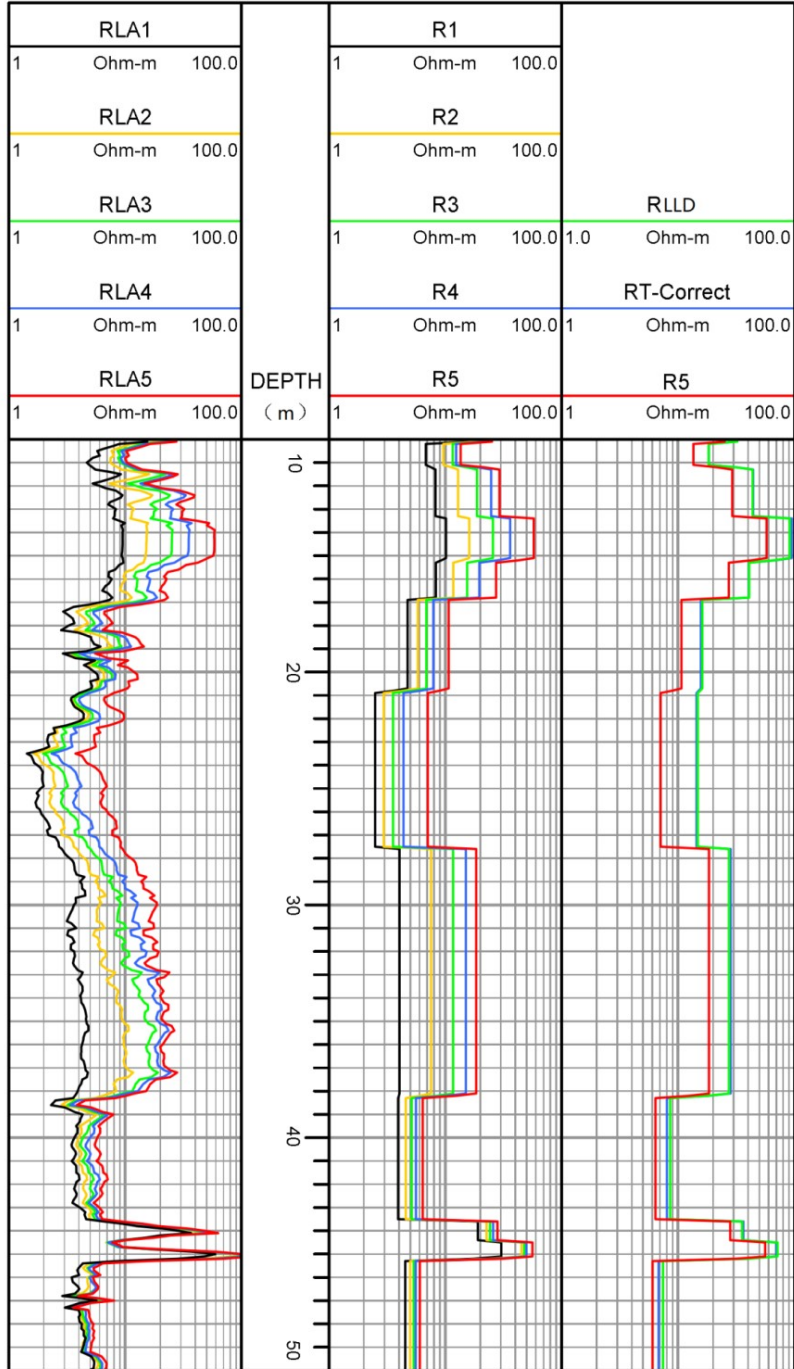

Fig. 9. The array laterolog curves in a well and the mud-filtrate invasion correction curve.

in Fig. 9. The first track from left displays the original array laterolog data and the second is the depth. The first two digits of depth are erased. The third track shows the layered resistivity curves. In the figure, the resistivity curves of different detection modes of the original array laterolog are separated with colors, and the resistivity increases gradually from the shallow to the deep detection mode. This is because the low resistivity mud filtrate invasion reduces the resistivity value near the borehole. The true resistivity obtained by different methods is compared in the fourth track. Red curve is the array laterolog data of deepest detection mode, the blue curve is the resistivity after mud-filtrate invasion correction for the same mode, and green curve is the resistivity of deep mode of dual lateral log. As is can be observed, the resistivity curve after mud-filtrate invasion correction is close to the deep lateral resistivity. Take the layer of $16 \sim 21 \mathrm{~m}$ as an example, HAL5/HAL3 $=1.554$, HAL5 $/ R_{i}=3.406$, which can be plotted on the mud-filtrate invasion correction chart. Based on the location of this data point $R_{t} / R_{i}$ is approximately 5 , and the invasion radius is about $0.35 \mathrm{~m}$. According to the ratio, the

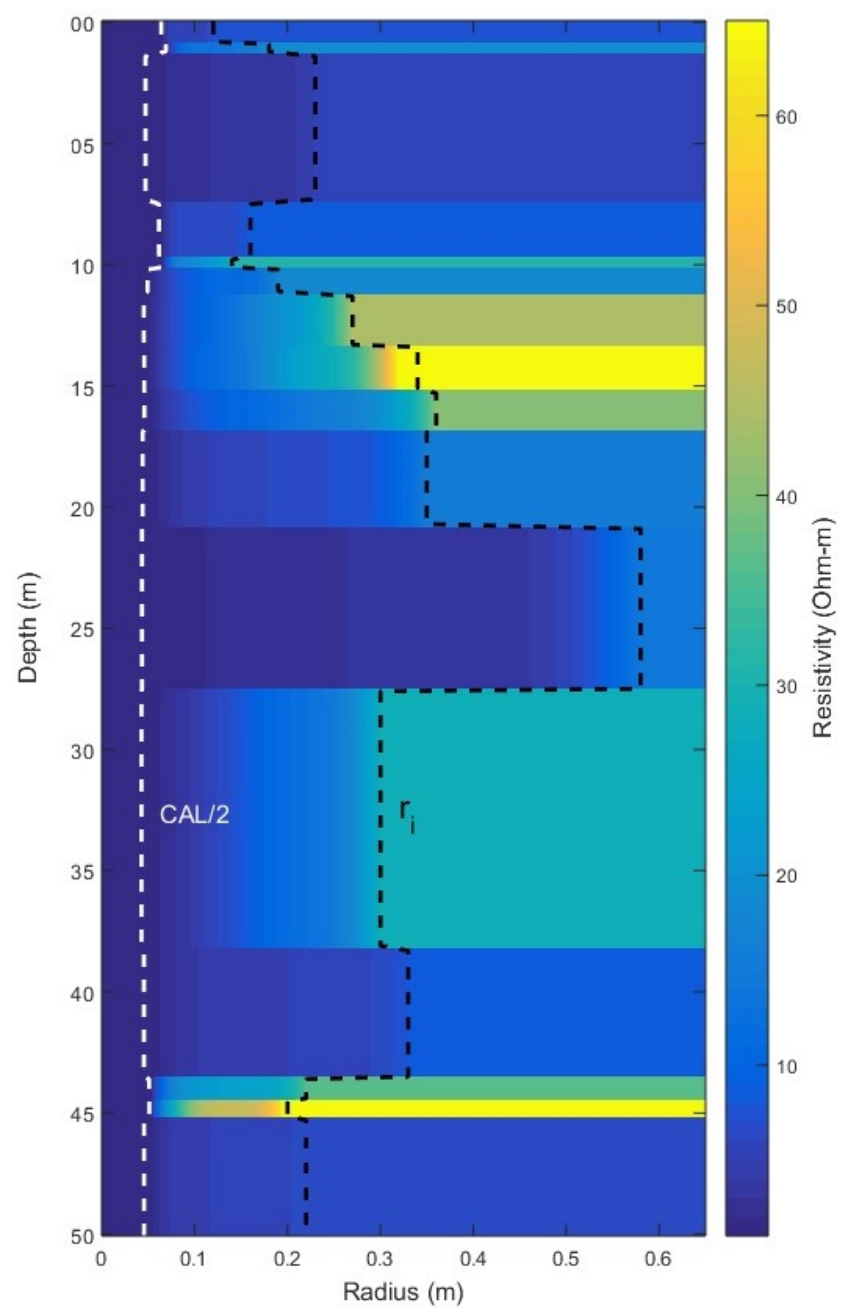

Fig. 10. Calculated radial distribution of resistivity of the well in the Fig. 9. White dotted line represents caliper log, black dotted line is the invasion radius obtained by correction chart and color scale indicates the resistivity.

true resistivity can be calculated:

$$
R_{t}=5 \times R_{i}=15.700
$$

After obtaining the mud-filtrate invasion depth and true formation resistivity values from the correction chart, the radial variation of resistivity can be graphed. Because the specific DOI of different detection modes are unknown, in this paper, the distance from the borehole wall $(C A L / 2)$ to the intrusion radius $\left(r_{i}\right)$ is divided into 5 segments. Thus, six radial depth points are obtained, while their resistivity values are assigned as $R_{m}$, HAL1, HAL2, HAL3, HAL4 and $R_{t}$, respectively. The resistivity of other radial depth points is obtained by spline interpolation, resulting in a radial distribution of resistivity, as shown in Fig. 10. The resistivity in the borehole is the mudfiltrate resistivity, which increases gradually from the borehole to invasion radius until it reaches the true resistivity of the formation. As can be seen from this figure, the invasion radius is the layer of $21 \sim 27.5 \mathrm{~m}$ is largest. It may because the shale content of this layer is high and permeability is low, thereby the invasion is slow. As a result, it is not easy to form mud 
cake, further, the invasion is deep. To a certain extent, the intrusion radius reflects some petrophysical properties.

\section{Conclusions}

Based on the differential equations and boundary conditions of the steady current field, and the principle of different detection modes of the array lateral logging, the finite element method is used to calculate the potential value at each node of main and monitoring electrodes, to obtain the numerical simulation of the array lateral logging response.

The increase of the borehole radius will increase the area affected by the mud-filtrate, thus the apparent resistivity of the array lateral logging will be reduced for the low resistivity mud-filtrate invasion. The impact of borehole on the apparent resistivity of each detection mode is different due to the different detection depths of each detection mode.

Mud-filtrate invasion makes the apparent resistivity of each detection mode different from the uninvaded formation. The larger the mud-filtrate invasion radius and the resistivity difference between invasion zone and uninvaded formation, the larger the impact of mud-filtrate invasion on the apparent resistivity will become.

Based on the effect of mud-filtrate intrusion on array laterolog response, the correction chart of mud-filtrate intrusion is developed. The depth of mud-filtrate invasion and the true formation resistivity can be obtained according to the correction charts. These two parameters can be used to provide the radial distribution of resistivity, reflecting some petrophysical properties. In addition, the chart has been successfully applied to the actual array laterolog data of a sandstone reservoir.

\section{Acknowledgments}

This paper is supported by the Fundamental Research Funds for Central Universities (China University of Geosciences, Wuhan) (CUG170619). The authors also thank the anonymous reviewers for their valuable and helpful comments.

Open Access This article is distributed under the terms and conditions of the Creative Commons Attribution (CC BY-NC-ND) license, which permits unrestricted use, distribution, and reproduction in any medium, provided the original work is properly cited.

\section{References}

Abdel-Shafy, T., Fattah, A.A., Corley, B., et al. Comparison of a new multi laterolog tool and a formation resistivity imager in the Phiops Field of Egypt. Paper SPE140692 Presented at SPE Middle East Oil and Gas Show and Conference, Manama, Bahrain, 25-28 September, 2011.

Chen, Y., Chew, W.C., Zhang, G. A novel array laterolog method. The Log Analyst 1998, 39 (5): 23-32.

Deng, S., Fan, Y., Li, Z., et al. Response characteristics of array lateral logs and their primary inversion in reservoirs with fracture-induced anisotropy. Pet. Sci. 2011, 8(1): 1116.

Deng, S., Li, Z., Fan, Y., et al. Numerical simulation of mud-filtrate invasion and its array laterolog response in deviated wells. Chinese Journal of Geophysics 2010, 53(4): 994-1000. (in Chinese)

Dun, Y., Tang, Z., Zhang, F., et al. Fast calculation and characteristic analysis of array lateral-logging responses. Int. J. Appl. Electrom. Mech. 2010, 33(1-2): 145-151.

Frenkel, M.A., Walker, M.J. Impact of array lateral logs on saturation estimations in two exploration wells from Australia. Paper SPWLA-2001-FFF Presented at SPWLA 42nd Annual Logging Symposium, Houston, Texas, 1720 June, 2001.

Galli, M.T., Gonfalini, M., Mele, M., et al. Resistivity modeling of array laterolog tools: An application in an offshore Norway clastic reservoir. Paper SPE77714 Presented at SPE Annual Technical Conference and Exhibition, San Antonio, Texas, 29 September-2 October, 2002.

Griffiths, R., Barber, T., Faivre, O. Optimal evaluation of formation resistivities using array induction and array laterolog tools. Paper SPWLA-2000-BBB Presented at SPWLA 41st Annual Logging Symposium, Dallas, Texas, 4-7 June, 2000.

Griffiths, R., Smits, J.W., Faivre, O., et al. Better saturation from new array laterolog. Paper SPWLA-1999-DDD Presented at SPWLA 40th Annual Logging Symposium, Oslo, Norway, 30 May-3 June, 1999.

He, F., Ma, X., Feng, L. HAL6505 array laterolog logging tool. Oil Forum 2013, 32(2): 59-61. (in Chinese)

Itskvich, G.B., Mezzatesta, A.G., Strack, K.M., et al. Highdefinition lateral log-resistivity device: Basic physics and resolution. Paper SPWLA-1998-V Presented at SPWLA 39th Annual Logging Symposium, Keystone, Colorado, 26-28 May, 1998.

Jarzyna, J.A., Cichy, A., Drahos, D., et al. New methods for modeling laterolog resistivity corrections. Acta Geophys. 2016, 64(2): 417-442.

Jiang, J. Forward modeling of array laterolog response. Qingdao, China University of Petroleum (East China), 2009. (in Chinese)

Li, D., Zheng, S., Tan, Y., et al. Application of Finite Element Method in Electric Well Logging. Beijing, Petroleum Industry Press, 1980. (in Chinese)

Li, S., Bittar, M.S. Focused array laterolog tool. U.S. Patent No. 9,239,402. 2016-1-19.

Liu, Z., Hu, Q. Computation and characteristics of array laterolog responses. J. Xi' an Shiyou University (Natural Science Edition) 2002, 17(1): 53-57. (in Chinese)

Liu, Z., Zhang, X. Multi parameter inversion of array laterolog response. J. Xi' an Shiyou University (Natural Science Edition) 2005, 20(1): 30-33. (in Chinese)

Maurer, H., Antonov, Y., Corley, B., et al. Advanced processing for a new array laterolog tool. Paper SPWLA2009-56708 Presented at SPWLA 50th Annual Logging Symposium, Woodlands, Texas, 21-24 June, 2009.

Nie, X., Li, S., Donderici, B., et al. Multi-array laterolog tools and methods with split monitor electrodes. U.S. Patent No. 9,081,114. 2015-7-14.

Pan, K., Tang, J., Du, H., et al. Trust region inversion algorithm of high-resolution array lateral logging in axisymmetric 
formation. Chinese Journal of Geophysics 2016, 59(8): 3110-3120. (in Chinese)

Pan, K., Wang, W., Tang, J., et al. Mathematical model and fast finite element modeling of high resolution array laterolog. Chinese Journal of Geophysics 2013, 56(9): 3197-3211. (in Chinese)

Phelps, G.D. Computation of mud filtrate invasion profiles. J. Can. Pet. Technol. 1995, 34(1): 18-27.

Salazar, J.M., Martin, A.J. Rock quality assessment using the effect of mud-filtrate invasion on conflicting borehole resistivity measurements. Geophysics 2012, 77(3): WA65-WA78.

Smits, J.W., Dubourg, I., Luling, M.G., et al. Improved resistivity interpretation utilizing a new array laterolog tool and associated inversion processing. Paper SPE49328 Presented at SPE Annual Technical Conference and Exhibition, New Orleans, Louisiana, 27-30 September, 1998.
Wang, H., Tao, G., Zhang, K. Wavefield simulation and analysis with the finite-element method for acoustic logging while drilling in horizontal and deviated wells. Geophysics 2013, 78(6): D525-D543.

Windarto Gunawan, A.Y., Sukarno, P., Soewono, E. Modelling of formation damage due to mud filtrate invasion in a radial flow system. J. Pet. Sci. Eng. 2012, 100: 99-105.

Wu, J., Xie, W., Xie, Q. Forward response analysis of array laterolog tool. J. Xi' an Shiyou University (Natural Science Edition) 2008, 23(1): 73-76. (in Chinese)

Yang, W. Forward and inversion of array laterolog logging data. Progress in Exploration Geophysics 2003, 26(4): 305-308. (in Chinese)

Yang, X., Meng, Y., Shi, X., et al. Influence of porosity and permeability heterogeneity on liquid invasion in tight gas reservoirs. J. Nat. Gas Sci. Eng. 2017, 37: 169-177.

Zhang, G. Electrical Logging Algorithm. Beijing, Petroleum Industry Press, 2009. (in Chinese) 